\title{
Mapping of the serotonin transporter locus (SLC6A4) to rhesus chromosome 16 using genetic linkage
}

\author{
J. Rogers ${ }^{a, b}$ J. Kaplan ${ }^{a}$ R. Garcia IV ${ }^{a}$ W. Shelledy ${ }^{a}$ S. Nair ${ }^{a}$ \\ J. Cameron ${ }^{\mathrm{c}}$ \\ a Department of Genetics, Southwest Foundation for Biomedical Research, San Antonio; \\ ${ }^{\mathrm{b}}$ Southwest National Primate Research Center, San Antonio, TX; \\ ${ }^{\mathrm{c}}$ Oregon National Primate Research Center, Beaverton, OR (USA)
}

Received 27 October 2004; accepted in revised form for publication by T. Haaf, 1 September 2005.

\section{Rationale and significance}

Research in both humans and nonhuman primates has shown that the serotonin transporter gene (SLC6A4, also referred to as 5-HTT or SERT) can exert significant influence on individual variation in neurophysiology and expressed behavior. The upstream promoter region of human SLC6A4 contains a series of tandem repeats. The number of repeated sequences within the promoter varies among people, and this variation is associated with changes in in vitro gene expression (Heils et al., 1996). Evidence shows that this promoter region polymorphism influences anxiety-related personality traits in humans (Lesch et al., 1996). The same polymorphism has been associated with increased neuronal activity in the amygdala in response to fearful stimuli (Hariri et al., 2002), and differential response to stressful life experience (Caspi et al., 2003), leading to individual differences in likelihood of suffering clinical depression. The SLC6A4 locus in nonhu-

This work was funded by NIH grant R24-RR015383 to J. Rogers and R01MH062586 to J. Cameron. We gratefully acknowledge the veterinarians and animal care staff of the Southwest National Primate Research Center and Oregon National Primate Research Center who facilitated the collection of blood and/or tissue samples.

Corresponding author: Jeffrey Rogers

Department of Genetics, Southwest Foundation for Biomedical Research 7620 N.W. Loop 410

San Antonio, Texas 78227 (USA)

telephone: +1 210258 9532; fax: +1 2106703344

e-mail: jrogers@darwin.sfbr.org man primates also contains repetitive elements in the upstream promoter region (Lesch et al., 1997). Rhesus monkeys (Macaca mulatta) exhibit a common repeat unit polymorphism that is similar in structure and located close to the human repeat polymorphism, but the allelic variation among rhesus monkeys is not identical to the human polymorphism. Nevertheless, the polymorphism in rhesus also has functional effects. Trefilov et al. (2000) found that free-ranging rhesus monkeys carrying two copies of the short allele (s) dispersed from their natal groups at an earlier age than did either the carriers of two long alleles (l) or heterozygotes. Bennett et al. (2002) showed that the rhesus polymorphism (1 vs. s) alters in vitro gene expression in this species as well, and that when animals are raised in peer groups (as opposed to motherreared), the SLC6A4 polymorphism can influence levels of serotonin metabolites found in the cerebrospinal fluid. Champoux et al. (2002) found that variation in the temperament of infant rhesus macaques is associated with SLC6A4 genotype. More recently, Barr et al. (2004) found an interaction between SLC6A4 genotype and early rearing experience that regulates activation of HPA axis stress response. Bethea et al. (2004) showed that infant rhesus monkeys that carry the s/s genotype exhibit increases in certain fear responses and are behaviorally inhibited when challenged with a series of tests involving stimuli that induce mild fear or anxiety. Clearly, individual variation in the SLC6A4 gene can influence individual variation in several aspects of neurobiology, stress reactivity and expressed behavior.

The goal of the present study is to establish the chromosomal position of the SLC6A4 gene within the rhesus genome. As part of a larger program in comparative primate genomics,
KARGER $\quad$ Fax +41613061234 www.karger.com (c) 2006 S. Karger AG, Basel

$1424-8581 / 06 / 1124-0341 \$ 23.50 / 0$ 
we have generated a genetic linkage map of the rhesus genome (http://www. snprc.org/linkage/index.html). This map of the rhesus genome consists of microsatellite loci that were previously mapped in the human genome. The current map covers all 20 rhesus autosomal chromosomes, and has an average spacing between loci of 9.3 centiMorgans. Comparison of chromosome organization between humans and rhesus monkeys showed that the order of loci on human chromosome 17 (HSA17) is different from the order of loci on the rhesus monkey homologue of HSA17, which is rhesus chromosome 16 or MML16. (See Moore et al., 1999 for a discussion of rhesus chromosome nomenclature.) This observation, i.e. that the arrangement of genetic loci on chromosomes HSA17 and MML16 is not conserved, raises questions concerning the chromosomal location of the serotonin transporter locus in the rhesus monkey genome. Therefore, in order to provide direct information concerning the chromosomal location of $S L C 6 A 4$ in the rhesus genome, and thus to facilitate comparative investigation of the potential effects of chromosomal position on the function of $S L C 6 A 4$, we analyzed the commonly studied length polymorphism in the upstream promoter and used genetic linkage methods to map the rhesus monkey serotonin transporter gene.

\section{Materials and methods}

\section{Population sampling}

Whole blood or tissue was obtained from 736 pedigreed rhesus macaques housed at the Southwest National Primate Research Center in San Antonio, Texas, and at the Oregon National Primate Research Center in Beaverton, Oregon. Genomic DNA was isolated from white blood cells or liver using standard phenol/chloroform extraction methods. The 736 rhesus monkeys analyzed are members of five extended families or pedigrees, each consisting of three generations. All procedures using animals were approved by the appropriate animal care and use committees.

Genotyping of the serotonin transporter polymorphism in rhesus

We amplified the polymorphic region of the rhesus monkey serotonin transporter promoter (Lesch et al., 1997) using the following primers: Forward-5'CAGCACCTAACCCCCTAATGTCCCTG3' and Reverse5'GATTCTGGTGCCACCTAGACGCCAG3'. The forward primer was fluorescently labeled. The PCR amplifications were done in $6 \mu 1$ total volume using the following reagents: 50 ng genomic DNA, $1 \times$ buffer (10 mM Tris- $\mathrm{HCl}, \mathrm{pH} 8.3,50 \mathrm{mM} \mathrm{KCl}, 1.5 \mathrm{mM} \mathrm{MgCl}$ ), $10 \mu \mathrm{M}$ each primer, $200 \mu \mathrm{M}$ each dNTP, 0.25 units of TaKaRa Taq polymerase, and additional magnesium to bring the final $\mathrm{MgCl}_{2}$ concentration to $2.0 \mathrm{mM}$. The nucleotide mix included $7^{\prime}$ deaza dGTP in a ratio of 9 parts $7^{\prime}$ deaza dGTP to one part dGTP. PCR thermal cycles consisted of 4 min at $95^{\circ} \mathrm{C}$ followed by 37 cycles of $94^{\circ} \mathrm{C}$ for $40 \mathrm{~s}, 61^{\circ} \mathrm{C}$ for $30 \mathrm{~s}, 72^{\circ} \mathrm{C}$ for $30 \mathrm{~s}$. Amplification was completed with a $7-\mathrm{min}$ extension at $72^{\circ} \mathrm{C}$ and then a hold at $4^{\circ} \mathrm{C}$.

The resulting PCR products were analyzed on ABI377 Automated DNA Sequencers using GeneScan Analysis (V. 3.1.2) and Genotyper (v. 2.5) software. Details of PCR protocols, primer sequences and allele categories for the linked microsatellite markers on MML16 used to establish the relative position of SLC6A4 are available on the website of the Southwest National Primate Research Center (http://www.snprc.org/ linkage/ index.html).

Linkage analysis

Genotypes for pedigreed rhesus were analyzed for Mendelian inheritance in the known pedigrees, and incompatible genotypes were re-checked. Pair-wise linkage analysis using final genotypes was per-
Table 1. Genotype frequencies for the SLC6A4 promoter polymorphism in the Oregon and Southwest National Primate Research Center colonies of rhesus macaques

\begin{tabular}{lcc}
\hline Genotype & Observed & $\begin{array}{l}\text { Frequency } \\
(\%)\end{array}$ \\
\hline$s / s$ & & 2.3 \\
$s / l$ & 17 & 25.6 \\
$s / x l$ & 188 & 0.5 \\
$l / l$ & 4 & 67.7 \\
$l / x l$ & 498 & 3.9 \\
\hline
\end{tabular}

formed using CRI-MAP (v. 2.41m) linkage analysis software (Green, unpublished data; Lander and Green, 1987). Following pair-wise analysis, a framework map for MML16 was developed using CRI-MAP and MultiMap (v. 2.0) map construction software (Matise et al., 1994). Loci that could not be placed in unique order with sufficient confidence (unique order at least 1000 times more likely that any alternative order) were located within broader, estimated map regions. The FLIPS function within CRI-MAP was used to assess the likelihood of alternative orders. This function inverts sets of adjacent loci (sets of two or more), then compares likelihoods among alternative arrangements. Only when a given order was at least 1000 times more likely than all others was it accepted. After the initial mapping, all microsatellite genotypes were checked for previously undetected errors using SimWalk282 (Sobel and Lange, 1996). Data problems detected by SimWalk were corrected within that program using algorithms that identify and eliminate the incompatible genotypes with lowest likelihood (i.e. those most likely to be incorrect). Final multipoint linkage maps were then constructed using Multi-Map (v 2.0) and CRI-MAP, including the FLIPS function.

\section{Results and discussion}

Among the rhesus monkeys tested, we found three alleles for the serotonin transporter promoter polymorphism. In this study population, the long allele (1) had a frequency of $82.4 \%$, the short allele (s) occurred at $15.4 \%$ and the very long allele (xl, 21 basepairs longer than the 1 allele) was observed at $2.2 \%$. Genotype counts and frequencies are presented in Table 1. Our results indicating that the long allele (1) was the most common and the very long form (xl) was the least frequent are concordant with previous studies of other rhesus populations. Inheritance of these three alleles in our threegeneration rhesus pedigrees followed Mendelian expectations.

Linkage analysis provided strong evidence for linkage of the SLC6A4 locus to rhesus chromosome 16, which is homologous to human chromosome 17. The pairwise LOD score between SLC6A4 and D17S1290 was 10.17 with $\theta=0.13$, and the score between SLC6A4 and D17S921 was 3.30 with $\theta=0.20$. Peak evidence for linkage between SLC6A4 and other loci placed more distantly from SLC6A4 on the same chromosome ranged from 1.17 to 2.34. Figure 1 shows the multipoint linkage map based on the results from CRI-MAP and Multi-Map. The overall structure of MML16 is similar, 
RHESUS

HUMAN

D17S938 - D17S938

23.7

D17S921 D D $\longrightarrow$ S921

13.8

SLC6A4 $-S L C 6 A 4$

${ }^{11.1} \mathrm{D} 17 \mathrm{~S} 129 \mathrm{DQ}$ D17S800

13.5

${ }_{\mathrm{D} 17 \mathrm{~S} 791}^{\mathrm{D} 17 \mathrm{~S} 791}$

Fig. 1. Comparative map of a region within human chromosome 17 (HSA17) and rhesus chromosome 16 (MML16). The order of loci in humans is taken from publicly available physical maps (www.ncbi.nih.gov). Distances among rhesus loci are shown in Kosambi centiMorgans as estimated by CRI-MAP and MultiMap.

but not identical, to locus order on HSA17. Specifically, our data indicate that a rearrangement has occurred in either the human or the rhesus evolutionary lineage such that D17S1290, which is located distally on the human chromosome, is located closer to the centromere in rhesus monkeys. However, the location of SLC6A4 relative to D17S921 is apparently conserved in the two species.

This study indicates that the arrangement of genetic loci differs between human chromosome 17 and its homologue in the rhesus monkey genome. Placement of SLC6A4 between D17S921 and D17S1290 in the rhesus genome allows investigators to infer the position of $S L C 6 A 4$ relative to other genes along this chromosome. Future studies intended to define the nature of this evolutionary rearrangement more precisely, and to identify specific functional genes whose positions relative to $S L C 6 A 4$ differ in rhesus monkeys versus humans may be warranted.

\section{References}

Barr CS, Newman TK, Shannon C, Parker C, Dvoskin RL, Becker ML, Schwandt M, Champoux M, Lesch KP, Goldman D, Suomi SJ, Higley JD: Rearing condition and rh5-HTTLPR interact to influence limbic-hypothalamic-pituitaryadrenal axis response to stress in infant macaques. Biol Psychiatry 55:733-738 (2004).

Bennett AJ, Lesch KP, Heils A, Long JC, Lorenz JG, Shoaf SE, Champoux M, Suomi SJ, Linnoila MV, Higley JD: Early experience and serotonin transporter gene variation interact to influence primate CNS function. Mol Psychiatry 7:118-122 (2002).

Bethea CL, Streicher JM, Coleman K, Pau FK, Moessner R, Cameron JL: Anxious behavior and fenfluramine-induced prolactin secretion in young rhesus macaques with different alleles of the serotonin reuptake transporter polymorphism (5HTTLPR). Behav Genet 34:295-307 (2004).

Caspi A, Sugden K, Moffitt TE, Taylor A, Craig IW, Harrington H, McClay J, Mill J, Martin J, Braithwaite A, Poulton R: Influence of life stress on depression: moderation by a polymorphism in the 5-HTT gene. Science 301:386-389 (2003).

Champoux M, Bennett A, Shannon C, Higley JD, Lesch KP, Suomi SJ: Serotonin transporter gene polymorphism, differential early rearing, and behavior in rhesus monkey neonates. Mol Psychiatry 7:1058-1063 (2002).

Hariri AR, Mattay VS, Tessitore A, Kolachana B, Fera F, Goldman D, Egan MF Weinberger DR: Serotonin transporter genetic variation and the response of the human amygdala. Science 297:400-403 (2002).

Heils A, Teufel A, Petri S, Stober G, Riederer P, Bengel D, Lesch KP: Allelic variation of human serotonin transporter gene expression. J Neurochem 66 : 2621-2624 (1996).

Lander ES, Green P: Construction of multilocus genetic linkage maps in humans. Proc Natl Acad Sci USA 84:2363-2367 (1987).

Lesch KP, Bengel D, Heils A, Sabol SZ, Greenberg BD, Petri S, Benjamin J, Muller CR, Hamer DH, Murphy DL: Association of anxiety-related traits with a polymorphism in the serotonin transporter gene regulatory region. Science 274:1527-1531 (1996).

Lesch KP, Meyer J, Glatz K, Flugge G, Hinney A, Hebebrand J, Klauck SM, Poustka A, Poustka F, Bengel D, Mossner R, Riederer P, Heils A: The 5-HT transporter gene-linked polymorphic region (5-HTTLPR) in evolutionary perspective: alternative biallelic variation in rhesus monkeys. Rapid communication. J Neural Transm 104:1259-1266 (1997).

Matise TC, Perlin M, Chakravarti A: Automated construction of genetic linkage maps using an expert system (MultiMap): a human genome linkage map. Nat Genet 6:384-390 (1994).

Moore CM, Janish C, Eddy CA, Hubbard GB, Leland MM, Rogers J: Cytogenetic and fertility studies of a rheboon, rhesus macaque (Macaca mulatta) $\times$ baboon (Papio hamadryas) cross: further support for a single karyotype nomenclature. Am J Phys Anthropol 110:119-127 (1999).

Sobel E, Lange K: Descent graphs in pedigree analysis: applications to haplotyping, location scores, and marker-sharing statistics. Am J Hum Genet 58:13231337 (1996).

Trefilov A, Berard J, Krawczak M, Schmidtke J: Natal dispersal in rhesus macaques is related to serotonin transporter gene promoter variation. Behav Genet 30:295-301 (2000) 